\title{
Convention: An Interdisciplinary Study
}

\author{
Luca Tummolini
}

Published online: 10 July 2008

(C) Springer Science+Business Media B.V. 2008

In our lives we are used to face situations in which something we all desire depends on the coordinated action of our peers. If we were to solve the practical problem of what to do in these situations from scratch, our daily life would be constantly at risk or even impossible. Luckily enough social life is full of patterns that we are able to discern in order to predict what the others will do, and that, at the same time, give us reasons to keep behaving as we have done before. Some of such regularities are what we call conventions, and to this 'tòpos' this special issue is devoted.

But, what makes a social regularity into a convention?

It has been 40 years since the first publication of David Lewis' seminal essay on this topic (Lewis 1969), and his book has proved to be a source of inspiration for many practitioners in different fields. Lewis' theory was developed as a response to Quine's attack at the notion of analyticity in philosophy of language, and was intended also as a unifying approach to the study of 'languages' as formal semantic models, and 'language' as a historical and social phenomenon. Intuitively, it is by convention that a population uses a certain language instead of another. But to clarify this platitude, one needs a theory of what a convention is.

The relevance of a theory of conventions of course spans well beyond the study of language. Language, in fact, is just one among many activities that are governed by conventions. Conventional regularities can be found at the core of morality, law, economics and in practically any of the

L. Tummolini $(\bowtie)$

Institute of Cognitive Sciences and Technologies,

Via San Martino della Battaglia 44, 00185 Roma, Italy

e-mail: luca.tummolini@istc.cnr.it daily activities we engage in. Nonetheless, a shared view on this issue is still missing.

Notoriously, Lewis took advantage of game theory to approach the problem, and in doing so he also innovated game theory itself in ways that are nowadays being rediscovered (Cubitt and Sugden 2003). However, from the onset he also advised the reader that game theory was scaffolding, and he showed this to be true in his rejoinder to the problem few years after his first take (see Lewis 1975). In any case, the basic theoretical proposal was preserved so that conventions of a population of agents turned to be regularities in action (or alternatively in action and belief) which are arbitrary but perpetuate themselves because they serve some sort of common interest. Past conformity to such regularity gives everyone a reason to go on conforming in the present instance, so that the regularity is constantly re-produced. However, an alternative regularity would have been maintained in the same way if everybody conformed to it in the first place.

This concise formulation, of course, hides many of the difficulties that need to be accounted for to fully understand the phenomenon. Nothing is said on how a specific convention originates in the first place (what is the appropriate evolutionary dynamics of a certain regularity of behavior?), on how the agents coordinate their private representations on the salient pattern to follow (what is the correct pattern between the many apt to describe the regularity? how does it happen that all agents in a population share the same representation of the situation and the regularity to follow?), of how much and what kind of knowledge of the convention each agent needs to dispose in order to conform (do conventions really need to be matter of common knowledge?), on the kind of reasoning, if any, that the agents endorse in order to decide to conform (is conformity to a convention justified by reasoning or do we conform 
just out of habit? is there any specific reasoning behind the sort of joint actions that are typically the object of conventions?), on whether or not conformity to a convention is something which we ought to do even beyond our selfinterest (are conventions a species of norms? are norms just nothing more than conventions?).

Answering all these questions calls for the contribution of many different disciplines, from many areas of philosophy (philosophy of sociality, moral philosophy, philosophy of action, of mind, of language, of law, and logic) to several between the behavioral and the social sciences (cognitive science, linguistics, economics, anthropology and sociology). This is reflected in the rationale of this special issue, where each of the eleven contributions approaches the notion of convention from different perspectives, both theoretical and applicative, addressing distinct problems with a variety of methodologies.

Although, as the title intends to suggest, the special issue is partially in homage to Lewis' classic, each of the authors deals with the topic with his/her own specific twist and background, offering a new and critical assessment of Lewis' theory and of its range of application.

Gilbert for instance challenges the individualism on which the game theoretical account of conventions is founded, and contrasts Lewis' analysis with her own holistic account which is grounded in Durkheim's sociological tradition. Differently, as an economist, Binmore is concerned with the role of common knowledge for the establishment of conventions. Lewis, who first introduced the concept, made it part of the very definition of conventions. Unfortunately, Binmore argues, by adopting the standard formal model of common knowledge accepted by economists (Aumann 1976), such an appeal to common knowledge has the consequence that new conventions could not get started in large societies. If one wants to understand how conventions originate, 'evolutive' game theory is the correct approach to the problem. If, differently, as Sillari in the next contribution, one is interested in the epistemic justification of the agents' reason to conform to the prevailing conventional regularities, then the appeal to common knowledge still proves to be useful. Especially if one carefully reconstructs the peculiar way in which Lewis defined the concept, which, while having been too quickly dismissed (but see Clark 1996 and Cubitt and Sugden 2003), is still original and fruitful. Postema goes even further, and argues that the stock of common knowledge, which he reconstructs as a kind of 'experiential commons', is the common ground from which the agents reason adopting a non-standard form of practical reasoning: 'salience' reasoning. Such reasoning is seen in a non individualistic way proceeding from the first-person plural, where salience 'for us' can be detected, to the best decision for all the interacting agents. Pulling various strings together, Ross also considers Lewis' account as individualist in a problematic way. Offering a game theoretical reconstruction of both Gilbert's and Postema's critiques, he sets himself to show that such problematic individualism is not due to the formal apparatus used to explore strategic interaction. Standing with Binmore, he agrees that the origins of conventional regularities are better captured by evolutionary arguments. However, he also contends that the agents still have reasons to conform to such regularities, at least if one, as Ross suggests, is able to model people not as plain economic agents but as complex products of a socialization dynamics.

The next three articles explore the power and limits of various aspects of Lewis' notion of convention, to enlighten problems in particular domains. Verbeek defends at length the relevance of a 'conventionalist' analysis of moral norms, or at least of some of them. Moral norms seem to lack the property of arbitrariness that is typical of conventions. For this reason, many moral philosophers reject any analysis along these lines. However, Verbeek argues that the resources of the conventionalist approach can resist many objections of this sort, even if in the end some aspects of the theory must be corrected. Differently, both Millikan and Marmor revive the study of convention and language. Millikan focuses on the way linguistic conventions are spread. Lewis has suggested that the use and understanding of language involves the perception of new coordination problems as being like old ones: solvable with analogous linguistic tools. Millikan shows in details that such suggestion fits well with contemporary theories of language acquisition and change held by construction grammars (for an explicit link, see Croft 2000). Marmor, like Gilbert and Millikan, contrasts his own theory of conventions with Lewis, in order to challenge the classical view that the literal meaning of words is conventionally fixed. While conventions can specify borderline cases and include them into the extension under certain conditions, the use of a word is governed by norms and not by conventions on Marmor's analysis.

Finally, the last three contributions, again from different perspectives, raise a concern that echoes those investigated by Gilbert, Binmore, Postema and Ross: the problem of creating an 'intersubjective' space between the agents, in which their mental representations, and not only their overt behaviors, are coordinated. Favereau contrasts the two definition of convention provided by Lewis in his two publications on the topic (Lewis 1969, 1975), noting that the second is less widely acknowledged in the literature than the first. While originally Lewis treated conventions as regularities in action alone, he then revised his analysis and generalized it to cover also regularities in action and belief, which seem to better characterize the conventions of language he was primarily interested in. Favereau argues that 
this shift has more radical consequences than usually assumed because it implicitly puts forward a different conception of rationality: interpretive rationality. This form of rationality is at odds with the calculative one, which, in the end, is unable to cope with the collective perspective that agents adopt in their social interactions. Alterman, from the viewpoint of contemporary cognitive science, argues that in everyday activity agents must somehow 'agree' on which recurrent situation they are facing and which is the relevant regularity to follow: both the 'situation' and the 'regularity' always vary, but their representations need to be coordinated. Such problems are particularly demanding when developing computational models in which conventions do not have a fixed structure, but emerge during the unfolding of collaborative activities. In a similar vein, but adopting an 'interactivist' approach inspired by Piaget developmental psychology (Piaget 1954), Bickhard shows some basic defects of the beliefdesire propositional framework championed by Lewis, especially in dealing with the characteristic normativity of conventions (an issue raised also by Gilbert). The notion of convention that Bickhard defends is in terms of a joint interactive representation of a social situation: this makes it possible to ground the normativity of conventions in the implicit relations among the participants and offers a perspective to connect it to the more complex social ontology that we, as humans, are able to construct.

Even from a bird's eye view, these contributions show how fruitful an interdisciplinary study of conventions is. The tension between individualistic and collectivistic perspectives, the mediating role of intersubjectivity and common knowledge, the appeal to salience and normativity are themselves 'topoi' which recurrently emerge in all contemporary reflections on the nature of our social reality, and that, I hope, this special issue help to cast in a common framework.

Finally, though conventional, it is nonetheless sincere my deep acknowledgment of the help received by the journal associate editor, Fabio Paglieri, whom I thank for his neverending patience and precision, together with the many reviewers who all have enthusiastically accepted to assist me in the assessment of the contributions, and the authors that have shared with me the vision of this special issue.

\section{References}

Aumann R (1976) Agreeing to disagree. Ann Stat 4:1236-1239

Clark HH (1996) Using language. Cambridge University Press, Cambridge

Croft W (2000) Explaining language change: an evolutionary approach. Longman, Harlow, Essex

Cubitt R, Sugden R (2003) Common knowledge, salience and convention: a reconstruction of David Lewis' game theory. Econ Philos 19:175-210

Lewis D (1969) Convention: a philosophical study. Harvard University Press, Cambridge (MA)

Lewis D (1975) Languages and language. In: Gunderstone K (ed) Minnesota studies in the philosophy of science, vol VII. University of Minnesota Press (reprinted in his Philosophical Papers, vol 1, pp, 163-188).

Piaget J (1954) The construction of reality in the child. Basic Books, New York 